\title{
Antihyperlipidemic and Antioxidant Effects of the Mixture of Ginseng Radix and Crataegi Fructus: Experimental Study and Preliminary Clinical Results
}

\author{
Chang-Nam Ko ${ }^{1}$, Seong-Uk Park ${ }^{1 *}$, Gyu-Tae Chang ${ }^{2}$, Woo-Sang Jung ${ }^{1}$, Sang-Kwan Moon ${ }^{1}$, \\ Jung-Mi Park ${ }^{1}$, and Ki-Ho Cho ${ }^{1}$ \\ ${ }^{1}$ Department of Cardiovascular \& Neurologic Diseases, Kyung Hee University College of Oriental Medicine, \\ Seoul 130-701, Korea \\ ${ }^{2}$ Department of Oriental Pediatrics, Kyung Hee University College of Oriental Medicine, Seoul 130-701, Korea
}

\begin{abstract}
The mixture of Ginseng Radix and Crataegi Fructus (Gen-CF) was developed to increase the pharmacological effect of ginseng in the treatment of hypercholesterolemia and prevention of cardiovascular disease. This study evaluated the effects of Gen-CF on serum lipids of hypercholesterolemic rats in vivo, as well as its antioxidant activities in vitro, and explored its clinical effects on patients with hypercholesterolemia. In vitro, Gen-CF displayed 1,1-diphenyl-2-picrylhydrasyl and superoxide radical scavenging activities, and inhibited hemolysis induced by 2,2 -azobis-2-amidinopropane dihydrochloride in a dose-dependent manner. In vivo, Gen-CF significantly inhibited the increases of total cholesterol, low-density lipoprotein cholesterol and triglyceride in high cholesterol-diet and Triton WR-1339 models. It also significantly inhibited the decrease of high-density lipoprotein cholesterol in these models. In the clinical trial, Gen-CF significantly lowered total cholesterol, low-density lipoprotein cholesterol, triglyceride, total lipid and phospholipid, with no adverse events, including hepatic or renal toxicity. The data suggest that Gen-CF has the potential to treat hypercholesterolemia and prevent cardiovascular disease.
\end{abstract}

Keywords: Panax ginseng, Antioxidants, Cardiovascular diseases, Hypercholesterolemia

\section{INTRODUCTION}

Hypercholesterolemia is a major cause of cardiovascular disease (CVD), such as atherosclerosis and coronary heart disease [1]. CVD is the most common cause of mortality and morbidity worldwide [2]. Although several factors, such as cigarette smoking, high-fat diet, high blood pressure, physical inactivity, age, and heredity have significant roles in causing CVD, high blood cholesterol is mainly responsible for the onset of CVD [2,3]. Lowering serum cholesterol levels by drug or dietary interventions could reduce the risk of CVD. Therefore, it is worthwhile to develop new safe and effective cholesterol-lowering agents from natural products.

In arteries of hypercholesterolemic animals and patients, vascular superoxide production and oxidative stress are increased [4]. Oxidation of low-density lipoprotein cholesterol (LDL) is considered as an important step in the development of atherosclerosis. Oxidized LDL (ox-LDL) is cytotoxic to a variety of vascular cells [5], induces the synthesis of monocyte chemotatic protein-1[6], recruits inflammatory cells [7], and stimulates

\footnotetext{
(c) This is an Open Access article distributed under the terms of the Creative Commons Attribution Non-Commercial License (http://creativecommons.org/licenses/by-nc/3.0/) which permits unrestricted non-commercial use, distribution, and reproduction in any medium, provided the original work is properly cited.
}

Received 29 Oct. 2011, Revised 14 Apr. 2011, Accepted 14 Apr. 2011

*Corresponding author

E-mail: happyomd@khu.ac.kr

Tel: +82-2-440-6217, Fax: +82-2-440-6217 
the production of autoantibodies [8]. Antioxidants such as vitamin $\mathrm{E}$ that is supplied in the diet can prevent oxidation of LDL [9]. In addition to inhibition of LDL oxidation, antioxidant therapy produces beneficial effects on atherosclerosis and prevents the progression of atherosclerosis in animal models by limiting vascular oxidative stress and superoxide production [10-13].

The mixture of Ginseng Radix and Crataegi Fructus (Gen-CF) was developed to increase the pharmacological effect of ginseng in the treatment of hypercholesterolemia and prevention of CVD. Many reports suggested that ginseng and hawthorn fruit may have an antihyperlipidemic effect [14-18] and the ability to prevent oxidation of LDL [19-27]. The present study evaluated the effects of Gen-CF on serum lipids of hypercholesterolemic rats in vivo, as well as its antioxidant activities in vitro, and explored its clinical effects on patients with hypercholesterolemia.

\section{MATERIALS AND METHODS}

\section{Materials}

Gen-CF was prepared as a capsulated water extract (300 mg per capsule) of Gen-CF (Table 1). Each preparation was extracted twice with boiling water for $2 \mathrm{~h}$. These extracts were filtered and evaporated in a rotary vacuum evaporator and lyophilized. To standardize the quality of Gen-CF, ginseng radix ginsenoside $\mathrm{Rg}_{1}$ was quantitatively assayed as previously described [28].

\section{Subjects for clinical trial}

Inclusion criterion was that serum total cholesterol was more than $240 \mathrm{mg} / \mathrm{dL}$. Exclusion criteria included 1) diabetes mellitus, 2) hepatic or renal diseases, 3) cardio or cerebral vascular diseases within 3 months, 4) patients who had taken anti-hyperlipidemic agents, or steroids within 6 months, and 5) alcoholic abusers. Informed consents were obtained from all subjects after being given a full explanation of the study.

\section{Clinical trial design}

Subjects were administered Gen-CF (two capsules three times each day for 4 weeks). No dietary or exercise advice were provided, so that all subjects could maintain their normal life-style concerning diet and exercise. Serum lipids including total cholesterol (TC), triglyceride (TG), total lipid (TL), phospholipid (PL), high density lipoprotein cholesterol (HDL), and LDL were measured at baseline and after 4 weeks of medication. For each subject, 10 to $15 \mathrm{~mL}$ of blood was collected in blood col-
Table 1. Composition of the mixture of Ginseng Radix and Crataegi Fructus

\begin{tabular}{lcc}
\hline Constitutent herbs & Scientific name & Mass (g/capsule) \\
\hline Ginseng Radix & Panax ginseng Meyer & 1 \\
Crataegi Fructus & Crataegus pinnatifida BGE & 3 \\
Total & & 4 \\
\hline
\end{tabular}

lection tubes containing heparin after overnight fasting, and the analysis of serum lipids was performed using an enzymatic method with a model 7600-110 apparatus (Hitachi, Tokyo, Japan). Any possible adverse effect was monitored by physical examination during the treatment period. Hepatic and renal toxicity were assessed by aspartate transaminase (AST), alanine transaminase (ALT), blood urea nitrogen (BUN), and creatinine $(\mathrm{Cr})$.

\section{Animals and diets}

Sprague-Dawley male rats (200-250 g) were acclimatized for a week in colony cages. The animals were kept at a constant temperature $\left(22-26^{\circ} \mathrm{C}\right)$ and humidity (50$55 \%$ ), and were fed with commercial diet (Samyang, Seoul, Korea). Water was allowed ad libitum.

\section{1,1-Diphenyl-2-picrylhydrasyl radical scavenging activity}

Different concentrations of the extract were measured for hydrogen donating or radical scavenging ability, using the stable radical 1,1-diphenyl-2-picrylhydrasyl (DPPH), as previously described [29]. The reaction mixture containing $1 \mathrm{~mL}$ of a DPPH methanolic solution (0.1 $\mathrm{mM}$ ) plus $4 \mathrm{~mL}$ of the extract at different concentrations was incubated at room temperature for $30 \mathrm{~min}$ and the absorbance was measured spectrophotometrically at 520 $\mathrm{nm}$. The percent of DPPH discoloration of the sample was then calculated. The results were expressed as percent inhibition.

\section{Superoxide anion scavenging activity}

Superoxide anion scavenging activity of the Gen-CF extract was determined as previously described by measuring the superoxide radicals generated by the xanthine/ xanthine oxidase system [30]. A $0.02 \mathrm{~mL}$ volume of different concentrations of the extract, $3 \mathrm{mM}$ xanthine, 3 $\mathrm{mM}$ EDTA, $0.75 \mathrm{mM}$ nitro blue tetrazolium and $0.15 \%$ bovine serum albumin were added to $0.48 \mathrm{~mL}$ of $0.05 \mathrm{M}$ $\mathrm{Na}_{2} \mathrm{CO}_{3}$ buffer and incubated for $10 \mathrm{~min}$ at room temperature. The reaction was initiated by the addition of 6 $\mathrm{mU}$ xanthine oxidase and carried out at $25^{\circ} \mathrm{C}$ for $20 \mathrm{~min}$. After this period, the reaction was stopped by the addition of $6 \mathrm{mM} \mathrm{CuCl}_{2}$, and absorbance was measured at 
$560 \mathrm{~nm}$. The results were expressed as percent inhibition.

\section{Induced hemolysis in erythrocytes}

Hemolysis of erythrocytes mediated by $2,2^{\prime}$-azobis2-amidinopropane dihydrochloride (AAPH) was determined using a modification of a method described elsewhere [31]. Blood samples were obtained by cardiac puncture in heparinized tubes and centrifuged $(1,500$ rpm, $10 \mathrm{~min}$ ). After removing the supernatant, the pellet was washed three times with $0.15 \mathrm{M} \mathrm{NaCl}$. During the last washing, the erythrocytes were centrifuged $(1,500$ rpm, $10 \mathrm{~min}$ ). A $10 \%$ suspension of erythrocytes was prepared by adding phosphate buffered saline (PBS, $\mathrm{pH}$ 7.4). Test samples $(0.2 \mathrm{~mL})$ at different concentrations and $0.2 \mathrm{~mL}$ of $100 \mathrm{mM} \mathrm{AAPH}$ were added in succession to $0.2 \mathrm{~mL}$ of erythrocyte suspension. The reaction mixtures were incubated at $37^{\circ} \mathrm{C}$ for $3 \mathrm{~h}$ with gentle shaking. After incubation, an aliquot of the reaction mixture was diluted 20 times with PBS and centrifuged at $1000 \times g$ for $10 \mathrm{~min}$. The absorbance of the supernatant $(A)$ at 540 $\mathrm{nm}$ was read. Similarly, another aliquot of the reaction mixture was diluted with distilled water to yield complete hemolysis and the absorbance of the supernatant $(B)$ after centrifugation was measured at $540 \mathrm{~nm}$. Inhibition percentage of hemolysis exhibited by each sample was calculated by the equation $(1-A / B) \times 100 \%$.

\section{High cholesterol diet model}

Rats were given $1 \%$ cholesterol, $0.25 \%$ cholic acid, and $2.5 \%$ olive oil with a standard equilibrated diet (Samyang Seoul, Korea) for $2 \mathrm{wk}$. Then, 24 hypercholesterolemic rats were selected and randomly divided into four groups. The first group was given a high cholesterol diet and administered orally with Gen-CF extract (220 $\mathrm{mg} / \mathrm{kg}$ ) once a day for a wk (study group 1). The second group was similarly administered Gen-CF extract (440 $\mathrm{mg} / \mathrm{kg}$, study group 2 ). The third group was similarly administered lovstatin (50 mg/kg, positive control group). The fourth group was administered only normal saline (untreated control group). The fifth group was given only standard equilibrated diet during the whole study period and received normal saline for a wk (normal group). After a week of medication, animals were kept for overnight fasting and anesthetized with ether. Blood samples were obtained by cardiac puncture.

\section{Triton WR-1339 model}

Thirty rats were randomly assigned to the aforementioned five groups. After a week of acclimation, all groups except group five received an intraperitoneal injection of a 10\% aqueous solution of Triton WR-1339 (Sigma-Aldrich, St. Louis, MO, USA) at a dose of 200 $\mathrm{mg} / \mathrm{kg}$. Food was withdrawn $16 \mathrm{~h}$ prior to Triton WR1339 injection. In study group 1, Gen-CF extract (220 $\mathrm{mg} / \mathrm{kg}$ ) was administered orally once a day for 3 days; the last administration was $1 \mathrm{~h}$ before the injection. Using the same method, Gen-CF extract $(440 \mathrm{mg} / \mathrm{kg}$ ) was administered to the second group (study group 2) and lovstatin $(50 \mathrm{mg} / \mathrm{kg}$ ) to the third group (positive control group). The fourth group (untreated control group) was only injected with Triton WR-1339. The fifth group was injected with only normal saline (normal group). Blood samples were obtained by cardiac puncture $18 \mathrm{~h}$ after the injection of Triton WR-1339.

\section{Determination of serum lipopoproteins}

Blood samples were allowed to clot for 30 to $40 \mathrm{~min}$. Serum was separated after centrifugation $(3,000 \mathrm{rpm}$, $30 \mathrm{~min}$ ) and used for biochemical analysis. Analysis of blood serum for TG, TC, and HDL was performed using standard enzymatic assay kits (Asan Pharmacy, Seoul, Korea). LDL was determined using a LDL-cholesterol kit (bioMerieux, Marcy l'Etoile, France).

\section{Statistical analyses}

All results were expressed as mean \pm SD unless otherwise stated. Data were analyzed by one-way ANOVA followed by the Student-Newman-Keuls test for experimental study and paired t-test for clinical trial. A value of $p<0.05$ was considered significant. All calculations were performed using SPSS ver. 11.5 (SPSS, Chicago, IL, USA).

\section{RESULTS}

\section{Antioxidant activity of Ginseng Radix and Crataegi Fructus in vitro}

To explore antioxidant activity of Gen-CF, we determined inhibitory effects of Gen-CF on DPPH and superoxide radical generation, and AAPH-induced hemolysis. Gen-CF displayed DPPH and superoxide radical scavenging activities in a dose-dependent manner (Fig. 1A). Gen-CF also inhibited hemolysis induced by AAPH in a dose-dependent manner (Fig. 1B).

\section{Hypolipidemic activity of Ginseng Radix and Cra- taegi Fructus in vivo (high cholesterol diet model)}

The TC, LDL, and TG values of the high cholesterol diet group were significantly higher than those of the normal diet group $(p<0.001)$ (Table 2). Gen-CF (440 mg/ 
Table 2. Effects of the mixture of Ginseng Radix and Crataegi Fructus on serum lipid levels in high cholesterol diet induced hyperlipidemic rats

\begin{tabular}{lccccc}
\hline \multicolumn{1}{c}{ Group } & No. & TC $(\mathrm{mg} / \mathrm{dL})$ & LDL $(\mathrm{mg} / \mathrm{dL})$ & HDL $(\mathrm{mg} / \mathrm{dL})$ & TG $(\mathrm{mg} / \mathrm{dL})$ \\
\hline Normal & 6 & $82.0 \pm 2.81$ & $21.2 \pm 1.59$ & $36.5 \pm 1.97$ & $75.0 \pm 3.71$ \\
Control & 6 & $241.0 \pm 9.36^{\# \#}$ & $67.3 \pm 3.39^{\# \#}$ & $23.8 \pm 2.82^{\#}$ & $135.5 \pm 5.90^{\# *}$ \\
Gen-CF $220 \mathrm{mg} / \mathrm{kg}$ & 6 & $193.5 \pm 6.05^{* * *}$ & $60.7 \pm 3.13$ & $29.8 \pm 2.46$ & $117.2 \pm 8.53$ \\
Gen-CF $440 \mathrm{mg} / \mathrm{kg}$ & 6 & $166.5 \pm 5.19^{* * *}$ & $41.2 \pm 3.35^{* * *}$ & $31.7 \pm 2.75^{*}$ & $94.5 \pm 5.62^{* * *}$ \\
Lovastatin $50 \mathrm{mg} / \mathrm{kg}$ & 6 & $150.0 \pm 6.37^{* * *}$ & $36.8 \pm 2.99^{* * *}$ & $32.5 \pm 0.92^{* *}$ & $88.7 \pm 7.88^{* * *}$ \\
\hline
\end{tabular}

TC, total cholesterol; LDL, low-density lipoprotein cholesterol; HDL, high-density lipoprotein cholesterol; TG, triglyceride; Gen-CF, Ginseng Radix and Crataegi Fructus.

"Significantly different, compared with normal group $(p<0.01)$.

${ }^{\#}$ Significantly different, compared with normal group $(p<0.001)$

"Significantly different, compared with control group $(p<0.05)$.

"Significantly different, compared with control group $(p<0.01)$

"*t Significantly different, compared with control group $(p<0.001)$.
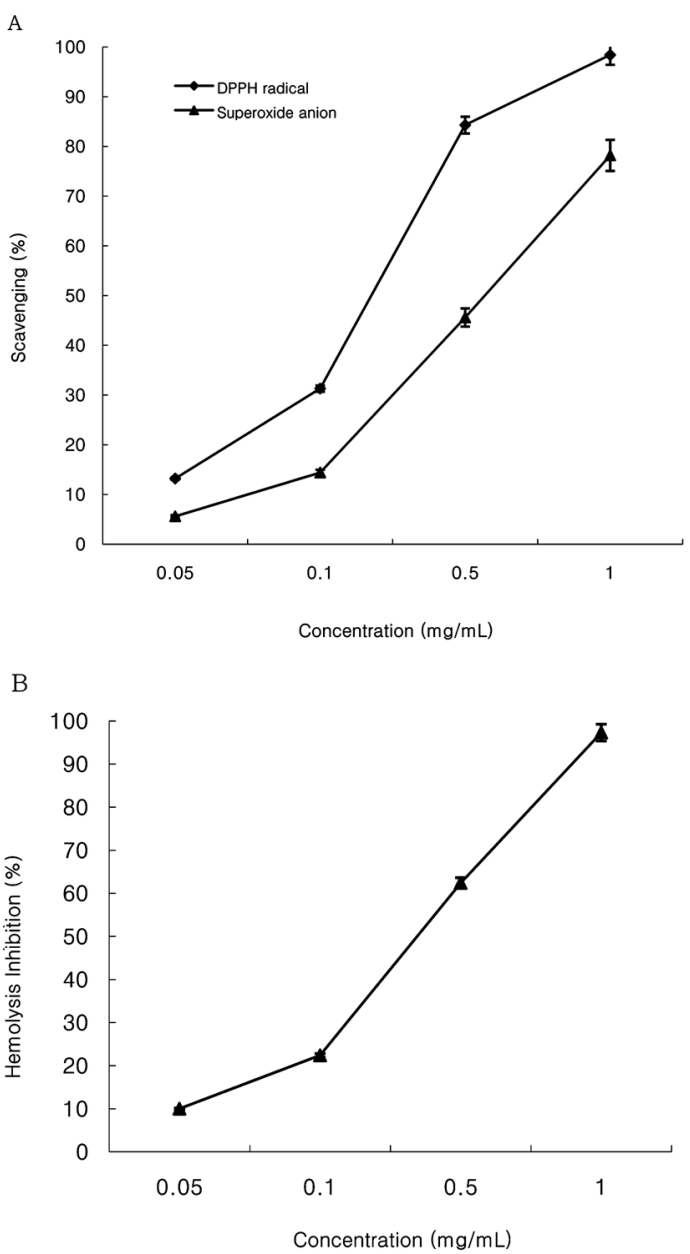

Fig. 1. Antioxidant activities of the mixture of Ginseng Radix and Crataegi Fructus (Gen-CF) in vitro. (A) Concentration-response curves for the scavenging of free radicals by Gen-CF. Data are expressed as percentage of scavenging of 1,1-diphenyl-2-picrylhydrasyl (DPPH), and superoxide radicals generated by the xantine/xantine oxidase system. (B) Concentration-response curve for the inhibition of homolysis by Gen-CF. Data are expressed as percentage of inhibition of 2,2'-azobis-2-amidinopropane dihydrochloride-induced hemolysis in erythrocytes. Values are mean $\pm S D$ of three different assays.

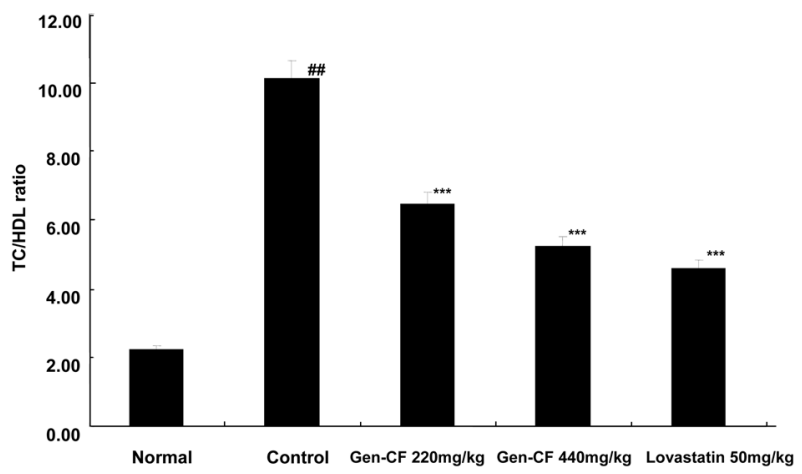

Fig. 2. Effects of the mixture of Ginseng Radix and Crataegi Fructus (Gen-CF) on TC/HDL ratio in high cholesterol diet induced hyperlipidemic rats. TC and HDL are total cholesterol and high-density lipoprotein cholesterol, respectively. \#\# Significantly different, compared with normal group $(p<0.001)$; ${ }^{* \star}$ Significantly different, compared with control group $(p<0.001)$

$\mathrm{kg})$ and lovastatin $(50 \mathrm{mg} / \mathrm{kg})$ significantly inhibited the increases of TC, LDL and TG values $(p<0.001)$. HDL was significantly lowered in the high cholesterol diet group, compared to the normal diet group $(p<0.01)$. GenCF $(440 \mathrm{mg} / \mathrm{kg})$ and lovastatin $(50 \mathrm{mg} / \mathrm{kg})$ significantly inhibited HDL decrease $(p<0.05$ and $p<0.01$, respectively) (Table 2). The TC/HDL ratio was significantly higher in the control group than that in the normal diet group (Fig. 2). Gen-CF (220 mg/kg), Gen-CF (440 mg/kg) and lovastatin $(50 \mathrm{mg} / \mathrm{kg})$ significantly inhibited the increase of TC/HDL ratio (Fig. 2).

\section{Hypolipidemic activity of Ginseng Radix and Cra- taegi Fructus in vivo (Triton WR-1339 model)}

The TC, LDL, and TG values in the Triton WR-1339 administered group were significantly higher than those in the normal diet group $(p<0.001)$ (Table 3$)$. Gen-CF $(440 \mathrm{mg} / \mathrm{kg})$ and lovastatin $(50 \mathrm{mg} / \mathrm{kg})$ significantly inhibited the increases of TC, LDL, and TG $(p<0.05$ and 
Table 3. Effects of the mixture of Gen-CF on serum lipid levels in Triton WR-1339 induced hyperlipidemic rats

\begin{tabular}{lccccc}
\hline \multicolumn{1}{c}{ Group } & No. & TC $(\mathrm{mg} / \mathrm{dL})$ & LDL $(\mathrm{mg} / \mathrm{dL})$ & HDL $(\mathrm{mg} / \mathrm{dL})$ & TG $(\mathrm{mg} / \mathrm{dL})$ \\
\hline Normal & 6 & $78.7 \pm 5.92$ & $11.7 \pm 1.43$ & $26.5 \pm 1.87$ & $102.5 \pm 7.61$ \\
Control & 6 & $249.2 \pm 22.6^{\# \#}$ & $81.2 \pm 5.16^{\# \#}$ & $15.8 \pm 1.98^{\#}$ & $323.7 \pm 7.61^{\# \#}$ \\
Gen-CF $220 \mathrm{mg} / \mathrm{kg}$ & 6 & $231.0 \pm 18.2$ & $75.2 \pm 7.74$ & $18.8 \pm 2.46$ & $296.5 \pm 19.2$ \\
Gen-CF $440 \mathrm{mg} / \mathrm{kg}$ & 6 & $182.0 \pm 13.0^{*}$ & $56.7 \pm 5.45^{*}$ & $22.7 \pm 1.95^{*}$ & $277.7 \pm 12.8^{*}$ \\
Lovastatin $50 \mathrm{mg} / \mathrm{kg}$ & 6 & $170.3 \pm 7.46^{* *}$ & $52.3 \pm 2.63^{* *}$ & $25.8 \pm 1.98^{* *}$ & $268.2 \pm 16.1^{* *}$ \\
\hline
\end{tabular}

Gen-CF, Ginseng Radix and Crataegi Fructus; TC, total cholesterol; LDL, low-density lipoprotein cholesterol; HDL, high-density lipoprotein cholesterol; TG, triglyceride.

"Significantly different, compared with normal group $(p<0.01)$.

\#Significantly different, compared with normal group $(p<0.001)$.

"Significantly different, compared with control group $(p<0.05)$.

"Significantly different, compared with control group $(p<0.01)$.

Table 4. General characteristics of the study subjects

\begin{tabular}{lc}
\hline & $(n=20)$ \\
\hline Male, $n(\%)$ & $9(45)$ \\
Age, yr (range) & $47 \pm 13.2(28-69)$ \\
Coronary artery disease, $n(\%)$ & $0(0)$ \\
Hypertension, $n(\%)$ & $5(25)$ \\
Total cholesterol $(\mathrm{mg} / \mathrm{dL})$ & $267.7 \pm 13.8$ \\
\hline
\end{tabular}

Table 5. Effects of the mixture of Ginseng Radix and Crataegi Fructus on serum lipid levels in patients with hypercholesterolemia

\begin{tabular}{ccc}
\hline$(\mathrm{mg} / \mathrm{dL})$ & Baseline & $4 \mathrm{wk}$ \\
\hline TC & $267.7 \pm 13.8$ & $238.8 \pm 23.1^{* *}$ \\
TL & $722.9 \pm 95.0$ & $681.6 \pm 110.8^{* *}$ \\
TG & $154.6 \pm 43.7$ & $134.1 \pm 34.8^{*}$ \\
PL & $290.9 \pm 26.0$ & $271.6 \pm 26.5^{* *}$ \\
HDL & $62.4 \pm 11.1$ & $61.8 \pm 9.5$ \\
LDL & $163.8 \pm 42.0$ & $150.2 \pm 20.0^{*}$ \\
\hline
\end{tabular}

Values are mean \pm SD.

TC, total cholesterol; TL, total lipid; TG, triglyceride; PL, phospholipids; HDL, high-density lipoprotein cholesterol; LDL, low-density lipoprotein cholesterol.

"Significantly different, compared with baseline $(p<0.05)$.

"Significantly different, compared with baseline $(p<0.01)$.

$p<0.01$, respectively). HDL was significantly lowered in the Triton WR-1339 administered group, compared to the normal diet group $(p<0.01)$. Gen-CF $(440 \mathrm{mg} / \mathrm{kg})$ and lovastatin $(50 \mathrm{mg} / \mathrm{kg})$ significantly inhibited HDL decrease $(p<0.05$ and $p<0.01$, respectively) (Table 3 ).

\section{Clinical effects of Gen-CF on serum lipid levels in patients with hypercholesterolemia}

The initial characteristics of the subjects are summarized in Table 4. Twenty-four subjects were recruited, but four dropped-out during the study. Therefore, 20 subjects were included in the final analysis. Gen-CF significantly
Table 6. Safety assessment data

\begin{tabular}{lccc}
\hline & \multicolumn{2}{c}{ Medication } & \\
\cline { 2 - 3 } & Before & After & \\
& $19.0 \pm 4.7$ & $16.7 \pm 3.9$ & NS \\
AST (U/L) & $19.3 \pm 9.0$ & $17.8 \pm 9.1$ & NS \\
ALT (U/L) & $14.8 \pm 5.2$ & $12.4 \pm 2.5$ & NS \\
BUN (mg/dL) & $0.9 \pm 0.3$ & $0.9 \pm 0.2$ & NS \\
Cr (mg/dL) & & & \\
\hline
\end{tabular}

Values are mean \pm SD.

AST, aspatate transaminase; ALT, alanine transaminase; BUN, blood urea nitrogen; $\mathrm{Cr}$, creatinine; NS, not significantly different.

lowered TC, TL, TG, PL, and LDL. But, HDL was not affected by Gen-CF administration (Table 5). There were no clinical adverse events during the 4 weeks of medication. There was no significant elevation of ALT, AST, BUN, and $\mathrm{Cr}$ (Table 6).

\section{DISCUSSION}

It is well-established that elevated blood lipid is a major risk factor for atheroclerosis. Lipids are very susceptible to attack by free radicals, and ox-LDL species appear to contribute to the atherosclerosis pathobiology within the artery wall $[5,32]$. In vitro studies have demonstrated that ox-LDL activates endothelial cells to increase the expression of chemoattractant molecules leading to stimulated transendothelial migration of monocytes and formation of foam cells. Ox-LDL also increases the production of growth factors, including platelet-derived growth factor, stimulating the migration and proliferation of smooth muscle cells $[33,34]$. Furthermore, ox-LDL impairs endothelium-derived nitric oxide production $[35,36]$.

Gen-CF was developed to increase the pharmacological effect of ginseng in the treatment of hypercholesterolemia and the prevention of CVD. The results of the present in vitro study show that Gen-CF has anti-oxidative 
activities, as demonstrated by radical scavenging activity and inhibition of AAPH-induced hemolysis. It appears likely that ginseng has antioxidant activities, based on the scavenging of DPPH and superoxide radicals, inhibition of AAPH-induced hemolysis and metal ion-induced lipid peroxidation, and increased superoxide dismutase activity and nitric oxide synthesis [22,25,37-39]. Hawthorn fruit was also reported to scavenge hydrogen peroxidase and superoxidase, and inhibit $\mathrm{Cu}^{2+}$-mediated lipid peroxidation $[26,27]$. Therefore, Gen-CF is thought to work by integrating the actions of both herbs, as most traditional herbal formulations do.

In addition to the antioxidant activity, Gen-CF displayed potent hypolipidemic activity, decreasing serum TC, TG, and LDL in both hypercholesterolemic models. The TC/HDL ratio is a better indicator of coronary heart disease risk than individual lipoprotein concentration $[40,41]$. In this study, the TC/HDL ratio of the Gen-CFtreated group was significantly lower than that of the control group in the high cholesterol diet model. GenCF also significantly lowered TC, TL, TG, PL, and LDL after 4 weeks of treatment in the patients. There were no adverse events, including hepatic or renal toxicity.

The mechanism by which Gen-CF decreases serum cholesterol remains unclear. Serum cholesterol can be lowered at several metabolic points including decreased synthesis, activation of LDL receptors, inhibition of the absorption of dietary cholesterol, and conversion of cholesterol to bile acids. It was previously reported that ginseng decreases blood cholesterol levels by increasing cholesterol excretion through bile acid formation $[42,43]$, and may increase LDL receptors by promoting the synthesis of LDL receptors in rats [44]. In one study, 3-hydroxy-3-methylglutaryl coenzyme A reductase activity was significantly lowered by ginseng, which shows that the mechanism of the hypocholesterolemic action of ginseng involves the suppression of cholesterol biosynthesis [14]. Hawthorn fruit was reported to increase LDLreceptor activity of hepatic membrane in rats [45] to increase excretion of bile acids through the up-regulation of hepatic cholesterol $7 \alpha$-hydroxylase activity, and inhibit cholesterol absorption through down-regulation of intestinal acyl CoA:cholesterol acyltransferase activity [16]. These actions may have also occurred in the present study.

To summarize, Gen-CF was able to reduce serum lipid levels in vivo, including in patients. Gen-CF also showed antioxidant activity through radical scavenging activity and inhibition of AAPH induced hemolysis. The data suggest that Gen-CF has the potential to treat hypercho- lesterolemia and prevent CVD.

The conclusions come with some caveats. The clinical trial had a small sample size and was not case-controlled. A large randomized controlled trial is needed. Secondly, there was no study on the mechanisms by which Gen-CF decreases serum cholesterol.

\section{ACKNOWLEDGEMENTS}

This research was supported by the 55th Kyung Hee University Anniversary Research Promotion Fund in 2003.

\section{REFERENCES}

1. Chobanian AV. Single risk factor intervention may be inadequate to inhibit atherosclerosis progression when hypertension and hypercholesterolemia coexist. Hypertension 1991;18:130-131.

2. Yokozawa T, Ishida A, Cho EJ, Nakagawa T. The effects of Coptidis Rhizoma extract on a hypercholesterolemic animal model. Phytomedicine 2003;10:17-22.

3. Farias RA, Neto MF, Viana GS, Rao VS. Effects of Croton cajucara extract on serum lipids of rats fed a high fat diet. Phytother Res 1996;10:697-699.

4. Ohara Y, Peterson TE, Harrison DG. Hypercholesterolemia increases endothelial superoxide anion production. $\mathrm{J}$ Clin Invest 1993;91:2546-2451.

5. Morel DW, Hessler JR, Chisolm GM. Low density lipoprotein cytotoxicity induced by free radical peroxidation of lipid. J Lipid Res 1983;24:1070-1076.

6. Rajavashisth TB, Andalibi A, Territo MC, Berliner JA, Navab M, Fogelman AM, Lusis AJ. Induction of endothelial cell expression of granulocyte and macrophage colony-stimulating factors by modified low-density lipoproteins. Nature 1990;344:254-257.

7. Navab M, Imes SS, Hama SY, Hough GP, Ross LA, Bork RW, Valente AJ, Berliner JA, Drinkwater DC, Laks H et al. Monocyte transmigration induced by modification of low density lipoprotein in cocultures of human aortic wall cells is due to induction of monocyte chemotactic protein 1 synthesis and is abolished by high density lipoprotein. $\mathrm{J}$ Clin Invest 1991;88:2039-2046.

8. Salonen JT, Yla-Herttuala S, Yamamoto R, Butler S, Korpela H, Salonen R, Nyyssonen K, Palinski W, Witztum JL. Autoantibody against oxidised LDL and progression of carotid atherosclerosis. Lancet 1992;339:883-887.

9. Esterbauer H, Dieber-Rotheneder M, Striegl G, Waeg G. Role of vitamin $\mathrm{E}$ in preventing the oxidation of lowdensity lipoprotein. Am J Clin Nutr 1991;53:314S-321S. 
10. Keaney JF Jr, Gaziano JM, Xu A, Frei B, Curran-Celentano J, Shwaery GT, Loscalzo J, Vita JA. Dietary antioxidants preserve endothelium-dependent vessel relaxation in cholesterol-fed rabbits. Proc Natl Acad Sci U S A 1993;90:11880-11884.

11. Marniemi J, Hakala P, Mäki J, Ahotupa M. Partial resistance of low density lipoprotein to oxidation in vivo after increased intake of berries. Nutr Metab Cardiovasc Dis 2000;10:331-337.

12. Nicolle C, Cardinault N, Gueux E, Jaffrelo L, Rock E, Mazur A, Amouroux P, Remesy C. Health effect of vegetable-based diet: lettuce consumption improves cholesterol metabolism and antioxidant status in the rat. Clin Nutr 2004;23:605-614.

13. Shafiee M, Carbonneau MA, Urban N, Descomps B, Leger CL. Grape and grape seed extract capacities at protecting LDL against oxidation generated by $\mathrm{Cu}^{2+}$, AAPH or SIN-1 and at decreasing superoxide THP-1 cell production. A comparison to other extracts or compounds. Free Radic Res 2003;37:573-584.

14. Muwalla MM, Abuirmeileh NM. Suppression of avian hepatic cholesterogenesis by dietary ginseng. J Nutr Biochem 1990;1:518-521.

15. Zheng X, Yan Y. The effect of ginsenosides of ginseng stem and leaf (GSL) on the lipid regulation and lipid peroxidation in chronic hyperlipidemic rabbits. Zhongguo Yaolixue Tonbao 1991;7:110-116.

16. Zhang Z, Ho WK, Huang Y, Chen ZU. Hypocholesterolemic activity of hawthorn fruit is mediated by regulation of cholesterol-7 $\alpha$-hydroxylase and acyl CoA: cholesterol acyltransferase. Food Res Int 2002;35:885-891.

17. Chen JD, Wu YZ, Tao ZL, Chen ZM, Liu XP. Hawthorn (shan zha) drink and its lowering effect on blood lipid levels in humans and rats. World Rev Nutr Diet 1995;77:147-154.

18. Von Eiff M, Brunner H, Haegeli A, Kreuter U, Martina B, Meier B, Schaffner W. Hawthorn/passion flower extract and improvement in physical exercise capacity of patients with dyspnoea class II of the NYHA functional classification. Acta Ther 1994;20:47-66.

19. Jung NP, Jin SH. Studies on the physiological and biochemical effects of Korean ginseng. Korean J Ginseng Sci 1996;20:431-471.

20. Attele AS, Wu JA, Yuan CS. Ginseng pharmacology: multiple constituents and multiple actions. Biochem Pharmacol 1999;58:1685-1693.

21. Shin HR, Kim JY, Yun TK, Morgan G, Vainio H. The cancer-preventive potential of Panax ginseng: a review of human and experimental evidence. Cancer Causes Control 2000;11:565-576.
22. Gillis CN. Panax ginseng pharmacology: a nitric oxide link? Biochem Pharmacol 1997;54:1-8.

23. Maffei Facino R, Carini M, Aldini G, Berti F, Rossoni G. Panax ginseng administration in the rat prevents myocardial ischemia-reperfusion damage induced by hyperbaric oxygen: evidence for an antioxidant intervention. Planta Med 1999;65:614-619.

24. Lee HJ, Kim DY, Chang CC. Antioxidant effects of Korean red ginseng components on the antioxidant enzymes activity and lipid peroxidation in the liver of mouse treated with paraquat. J Ginseng Res 1999;23:182-189.

25. Chen X. Cardiovascular protection by ginsenosides and their nitric oxide releasing action. Clin Exp Pharmacol Physiol 1996;23:728-732.

26. Zhang Z, Chang Q, Zhu M, Huang Y, Ho WK, Chen Z. Characterization of antioxidants present in hawthorn fruits. J Nutr Biochem 2001;12:144-152.

27. Bahorun T, Gressier B, Trotin F, Brunet C, Dine T, Luyckx M, Vasseur J, Cazin M, Cazin JC, Pinkas M. Oxygen species scavenging activity of phenolic extracts from hawthorn fresh plant organs and pharmaceutical preparations. Arzneimittelforschung 1996;46:1086-1089.

28. Hayakawa J, Noda N, Yamada S, Mikami E, Uno K. Studies on physical and chemical quality evaluation of crude drugs preparations. III. Analysis of gardenia fruits and its preparations. Yakugaku Zasshi 1985;105:9961000.

29. Blois MS. Antioxidant determinations by the use of a stable free radical. Nature 1958;181:1199-1200.

30. Amakura Y, Umino Y, Tsuji S, Ito H, Hatano T, Yoshida $\mathrm{T}$, Tonogai Y. Constituents and their antioxidative effects in eucalyptus leaf extract used as a natural food additive. Food Chem 2002;77:47-56.

31. Miki M, Tamai H, Mino M, Yamamoto Y, Niki E. Freeradical chain oxidation of rat red blood cells by molecular oxygen and its inhibition by alpha-tocopherol. Arch Biochem Biophys 1987;258:373-380.

32. Stocker R, Keaney JF Jr. Role of oxidative modifications in atherosclerosis. Physiol Rev 2004;84:1381-1478.

33. McMurray HF, Parthasarathy S, Steinberg D. Oxidatively modified low density lipoprotein is a chemoattractant for human T lymphocytes. J Clin Invest 1993;92:1004-1008.

34. Quinn MT, Parthasarathy S, Fong LG, Steinberg D. Oxidatively modified low density lipoproteins: a potential role in recruitment and retention of monocyte/macrophages during atherogenesis. Proc Natl Acad Sci U S A 1987;84:2995-2998.

35. Tanner FC, Noll G, Boulanger CM, Luscher TF. Oxidized low density lipoproteins inhibit relaxations of porcine coronary arteries. Role of scavenger receptor and endo- 
thelium-derived nitric oxide. Circulation 1991;83:20122020.

36. Cowan CL, Steffen RP. Lysophosphatidylcholine inhibits relaxation of rabbit abdominal aorta mediated by endothelium-derived nitric oxide and endothelium-derived hyperpolarizing factor independent of protein kinase C activation. Arterioscler Thromb Vasc Biol 1995;15:22902297.

37. Keum YS, Park KK, Lee JM, Chun KS, Park JH, Lee SK, Kwon H, Surh YJ. Antioxidant and anti-tumor promoting activities of the methanol extract of heat-processed ginseng. Cancer Lett 2000;150:41-48.

38. Chang MS, Lee SG, Rho HM. Transcriptional activation of $\mathrm{Cu} / \mathrm{Zn}$ superoxide dismutase and catalase genes by panaxadiol ginsenosides extracted from Panax ginseng. Phytother Res 1999;13:641-644.

39. Kim H, Chen X, Gillis CN. Ginsenosides protect pulmonary vascular endothelium against free radical-induced injury. Biochem Biophys Res Commun 1992;189:670676.

40. Stampfer MJ, Sacks FM, Salvini S, Willett WC, Hennekens $\mathrm{CH}$. A prospective study of cholesterol, apolipoproteins, and the risk of myocardial infarction. N Engl J Med
1991;325:373-381.

41. Kinosian B, Glick H, Preiss L, Puder KL. Cholesterol and coronary heart disease: predicting risks in men by changes in levels and ratios. J Investig Med 1995;43:443-450.

42. Yamamoto M, Kumagai A. Long term ginseng effects on hyperlipidemia in man with further study of its actions on atherogenesis and fatty liver rats. In: Korea Ginseng \& Tobacco Research Institute. Proceedings of the 4th International Ginseng Symposium at Korea, 1984. p.13-20.

43. Joo CN. The preventive effect of Korean ginseng saponins on aortic atheroma formation in prolonged cholesterol fed rabbits. In: Korea Ginseng \& Tobacco Research Institute. Proceedings of the 3rd International Ginseng Symposium at Korea, 1980. p.27-36.

44. Yokozawa T, Kobayashi T, Kawai A, Oura H, Kawashima Y. Hyperlipemia-improving effects of ginsenoside$\mathrm{Rb} 2$ in cholesterol-fed rats. Chem Pharm Bull (Tokyo) 1985;33:722-729.

45. Rajendran S, Deepalakshmi PD, Parasakthy K, Devaraj H, Devaraj SN. Effect of tincture of Crataegus on the LDLreceptor activity of hepatic plasma membrane of rats fed an atherogenic diet. Atherosclerosis 1996;123:235-241. 